\title{
Green Human Resource Management Bundle Practices and Manufacturing Organizations for Performance Optimization: a Conceptual Model
}

\author{
${ }^{1}$ Ahmed A. Zaid, ${ }^{1}$ Abdul Talib Bon and ${ }^{2}$ Ayham A.M. Jaaron \\ ${ }^{l}$ Department of Production and Operations Management Universiti Tun Hussein Onn Malaysia Parit Raja, Johor, Malaysia \\ ${ }^{2}$ Department of Industrial Engineering An-Najah National University Nablus, West Bank, Palestine \\ Corresponding Author Email: ahmedzaid1231986@gmail.com
}

\begin{abstract}
As growing amount of studies have focused on green human resources management (GHRM) practices that incorporate ecological thinking, these practices are expected to affect environmental impact of organizations. GHRM can help them achieve green corporate culture and enhance their performance. In this paper, GHRM practices as a bundle is taken into account instead of individual, which give numerous benefits to the organizations. This paper reviews the literature on the relationship between GHRM bundle practices and four dimensions of organization performance. This paper also proposes a conceptual model to exhibit the relationship between GHRM bundle practices and organization performance. Hence, manufacturing firms can identify an effective approach for applying GHRM practices that contribute to organizational performance.
\end{abstract}

Keywords: green human resource management, environmental performance, financial performance, operational performance, social performance.

\section{Introduction}

\begin{abstract}
"Green business" practices help organizations achieve greater financial savings that yield profits. These practices benefit natural systems and provide employees conducive working place in a socially sustainable manner [34]. Leading organizations in developed countries have implemented green practices to create awareness of environmental sustainability. However, the way how the organizations implement these practices are vague in Palestine. Organizations have come under scrutiny from stakeholders such as authoritarians, consumers, opponents, non-governmental organizations, and workers to ensure environmental and social sustainability in business operations [15];[41]. This issue arises due to the increasing demand from employees who require an environmentally friendly practice. Organizations have adopted green practices to reduce environmental woes and improve financial performance [46], thus they can become more sustainable [41]. The equipoise between ecological, economic, operational, and financial performance has become the main concern among organizations with competitive systems and society burdens.

The environmental issues have allowed organizations to create new regulations, policies, and intangible cultures over the last few decades. Organizations have to focus on the environmental impact by considering the interaction between their financial and social growth in terms of stand-alone virtues [28]. The vicissitudes of discernment in environmental sustainability, including legal requirement and pressing stakeholder, have affected the performance of organizations [2]. This enables organizations to link green human resource practices with corporate strategy to improve organizational performance [4]. In the light of this, green
\end{abstract}

human resources management (GHRM) has attracted considerable attention from business entities. It is concerned about the systemic and planned alignment of typical human resource management (HRM) practices with ecological objectives of the organizations. Therefore, harmonization between different functional areas and human resources is crucial [15]. GHRM practices are effective tools in making business sustainable. [9] highlighted that HRM has focused extensively on individual practices rather than a set of practices. Specifically, this study discerns human resource bundles can improve organizational performance. This is congruent with [35] study, which called for more studies on the relationship between GHRM bundle practices and organizational performance. The concept of GHRM bundle is mainly related to the configurationally viewpoint. This suggests that the consortium of interrelated elements within GHRM practices is internally reliable, which is consistent with different contextual factors and strategic orientation of a firm [3]. [24] affirmed that GHRM bundles bring about greater efficacy to design synergistic effects that are superior than any single GHRM practice on manufacturing firms' performance [7].

Environmental protection has become increasingly crucial for organizations as they are pressured by competitors, communities, and the governmental authorities. To minimise environmental pollution, GHRM practices are important starting from purchasing raw materials, manufacturing products, distributing products, selling products to disposing products. Industry plays a key role in the development of economic and social well-being in the Palestinian society. Industrial sector is the largest contributor to the country's environmental pollution issues that need to be 
assessed, monitored, and rectified [28]. Given that the industrial sector is significant to the Palestinian society, there is a need to adopt different environmentally friendly practices to manage environmental issues. However, GHRM practices are rarely adopted by manufacturing firms in Palestine since many of them are not sure how important the practices are to sustain the business. This study targeted Palestinian industries that have direct effect on human health and environment. Any efforts to minimize the environmental footprints of the industries are likely to strengthen environment protection and sustainable development.

The rest of the paper is structured as follows. Section 2 presents the literature of green human resource and organization performance. Section 3 illustrates the proposed conceptual model Section 4 discusses the hypotheses development. Then, Section 5 outlines sample, data collection and measurements. The last section delineates the discussion and conclusion.

\section{Literature Review}

The term, HRM, has been commonly used in organizations that focuses on the optimization of workforce and condition performance. For example, salary and benefits are important administrative issues in HRM [4]. At advanced level, HRM influences all aspects of strategic decision-making process directly. HRM is one of the most effective fractions of the management [10]. According to [34], the success of management strategy is highly contingent on the eminence of human resources that serve as the foundation of organizational strength. Greening human resource practices can improve organizational performance, which has a considerable impact on broader corporate and strategic issues of human resource practices and policies. It is important to include greener activities in every step of HRM activities. HRM practices support the implementation and maintenance of environmental management system in the organizations to achieve a better environmental performance [23]. Higher management patronage, environmental guidance, encouragement, and remunerations are imperative HRM practices to implement initiatives concomitant with environmental management system [13].

GHRM is part of the HRM functions to encourage an organization to take up green initiatives [26]. GHRM comes from the philosophy, policy, and practice of green management [31]. GHRM helps an organization to execute programs to decrease carbon emission, gain carbon credits, and other areas pertaining to manpower, induction, performance, supervision, training and development, compensation, and reward management [29].

GHRM is essential for greening organizations [5]. [11] stated that many firms implement GHRM to benefit their employees and financial performance. Besides the environment, GHRM also increases the retention of talent pool [31]. According to [19], firms can gain substantial achievement of engagement, commitment, morale, work-life quality and retention through fair and equitable GHRM. Many researchers have discussed what organizations could benefit from GHRM. [27] emphasised that organizations can focus on environmentally sustainable business practices by instigating greener corporate culture that leads to efficacy, lower expenditure and better employee relationship. GHRM practices can boost employees' well-being by cultivating positive work surroundings. It interposes the well-being and performance of the organizations constructively [35]. The advantages of GHRM include expenditure reduction, corporate social responsibility, talent management, and competition benefits (Aggarwal \&
Sharma, 2014). Besides that, GHRM attracts green talents by establishing green image on employer and improving the company's image as a potential marketing strategy. It contributes to the quality of the organization internally and externally and improves the relationship with multiple stakeholders such as customers, suppliers, vendors, shareholders, government agencies, employees, and the media.

[21] proposed a model that highlights adequate environmental training is crucial at various levels as part of GHRM to enhance financial and environmental performance, thereby attaining competitive advantage. Few studies have paid attention to the advantages of GHRM systems on organizational performance rather than individual practices [2] ; [37]. None of them has investigated the effect of GHRM bundle practices further on the performance of manufacturing firms from an operational and social point of view, which is expected to help firms reduce degradation of the environment. For instance, [25] examined the effect of a set of GHRM practices as a bundle on the environmental and financial performance of organizations. Using structural equation modeling (SEM), the study confirmed that GHRM practices as a bundle had a positive relationship with financial and environmental performance among 140 managers working in manufacturing and service firms in Italy. The present study investigate the influence of GHRM practices as a bundle on environmental, operational, financial, and social performance among Palestinian manufacturing firms. This study would like to contribute to the improvement in environment protection and sustainable development for manufacturing firms.

\section{Proposed Conceptual Model}

Based on the analysis of the literature, a conceptual framework is developed to investigate the relationship between GHRM bundle practices and environmental, financial, operational, and social performance (see Figure 1). Since recent GHRM literature has primarily focused on the effect on organizational performance of bundles of GHRM practices bundle [35], this study considers GHRM bundle as a cohesive set of human resource practices that has a consequence on manufacturing firm performance by (i) selecting ideal employees who are aware of environmental management of the organization. This is known as "green hiring" [38]. (ii) providing environmental training for members who are involved in greening activities to increase environmental awareness. This is known as "green training and involvement" [40]. (iii) offering a non- monetary and monetary compensation to members based on their environmental achievement. This is known as "green performance management and compensation" [14] , [25]. Researchers have suggested that financial, environmental, social, and operational performances are important indicators in environmental management [12] ; [45]. Therefore, this study measures organizational performance in terms of these four dimensions.

The below conceptual framework is supported by natural resource-based view by [18]. This theory suggests that an organization can gain competitive advantages from the natural environment. The environmental activities can produce strategic resources that are difficult to imitate [6] ; [21] ; [42]. To maximize the robustness and reliability of the results, firm size and environmental management system (EMS) are the two control variables introduced in this research. According to [28], these two variables had a significant effect on environmental practices. 


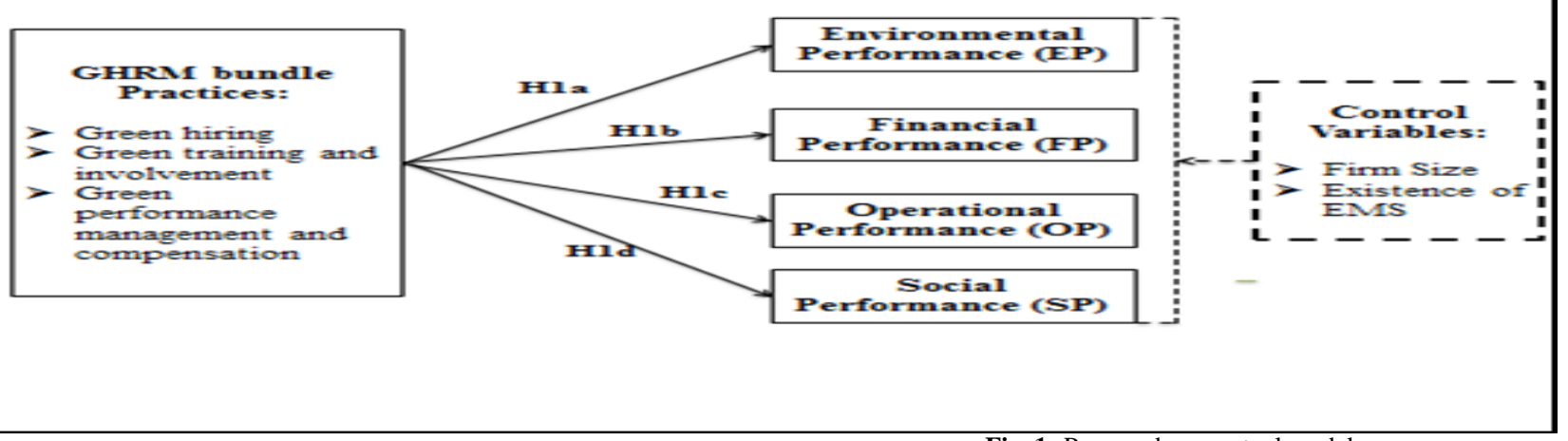

Fig. 1: Proposed conceptual model

\section{Hypotheses Development}

Green human resource requires employees to be fully involved in getting greener [43]. They should constantly practice green endeavours in their working area. This practice should also be included in recruitment, training, and compensation [44] to establish green human resources [34]. According to [24], GHRM bundle acts as adhesive that connects various practices as a synchronous unit. The mutual benefits between organizations and workers ought to signify the sequence of consistent and internally dependable HR practices. Incorporation of practices unveils greater impact on a company's improvement and performance [37].

Current literature stresses that organizations can adopt appropriate human resource practices to stimulate their employees in order to achieve environmental sustainability objectives. Exploration should be made to determine what engages employees in proenvironmental behaviour that helps organizations to become greener [30]. This is because firms cannot take further action without the support of their staff in terms of knowledge, skills, commitment, and productivity [47]. Green human resource endeavours strive to enhance competency, eradicate environmental damage, and restore human resource products, tools, and procedures with greater efficiency at lower costs. [15] highlighted the significance of putting 'greening' functions as the main factor in improving financial and environmental performance.

By understanding green human resource practices, organizations can improve their environmental performance in a sustainable manner [7]. Green human resource practices are effective in making organizations' operations green. Several authors have confirmed that financial performances are driven by employee outcomes that are associated with environmental-oriented practices such as competence, involvement, and motivation [20] ; [28]. Without doubt, hiring environmentally conscious workers can be appealing to an organization. The organization can encourage employees to get involved in environmental activities and provide them environmental training to improve their skills, motivation, retention, and job-related results [4] ; [39], thereby increasing the financial performance of the organizations.

In terms of operational performance, [8] investigated the relationship between HRM practices and operational performance in terms of efficiency, quality, and time-based measures. The study found HRM practices improved the firm's operational performance through high-commitment practices that fostered employees' aptitude for gaining quality and time. Moreover, [22] investigated the relationship between environmental management and operational performance among Brazilian automotive firms Jabbour and fellows looked into whether human resources practices interfered the greening process of these firms. The result indicated that human side of environmental management improved operational capabilities of the firms.

Apart from that, [43] claimed that organizations that invested in social responsibilities had gained tangible benefits in respect to customer and employee satisfaction, excellent staff recruitment, and innovation, which are likely to strengthen the firms' performance. As mentioned by [36], those manufacturing firms that invested in social programs took an important step to reinforce GHRM. The agenda of these programs must focus on health and safety of employees to prevent them from being exposed to detrimental emissions. Beside reporting role, mounting these programs is likely to enhance the performance of manufacturing firms sustainably. Given that GHRM bundle is expected to improve organizational performance, the following research hypotheses are developed:

H1a: GHRM bundle positively affects environmental performance.

H1b: GHRM bundle positively affects financial performance.

H1c: GHRM bundle positively affects operational performance.

H1d: GHRM bundle positively affects social performance.

\section{Sample, Data Collection and Measurements}

The population for this study is senior executives who are responsible for GHRM practices in Palestinian manufacturing firms. They are those having a good understanding of the variables. The study will invite 130 firms which are members of the Palestinian Industrial Federation representing the most industrial pollutant sectors such as food, pharmaceuticals, and chemicals [28]. The criteria of the participating firms are manufacturers that implement green practices. Of 130 manufacturing firms, 110 of them adopt GHRM practices [28]. The sample size of 110 is considered adequate for performing data analysis using SEM-Partial Least Squares (PLS) [16]. A survey questionnaire is designed to measure GHRM bundle (green hiring, green training and involvement, green performance management and compensation) and four dimensions of organizational performance (financial, environmental, operational, and social performance). PLS-SEM will be employed to test H1a, H1b, H1c, and H1d. It is a second-generation multivariate analytical tool for identifying a new theory (GHRM in the Palestinian context). SEM-PLS can determine the hypotheses and statistical properties of a conceptual framework, simultaneously [16]. It is prominently used in various management studies [32]. 


\section{Discussion and Conclusion}

According to the literature review, GHRM and organizational performance are associated with HRM. Although the majority of the studies [2] ; [37] have reported a significant relationship between these two variables, the implementation of GHRM bundle practices in manufacturing firm performance has not received much interest in Palestine. None of the studies have looked into the influence of GHRM bundle practices on manufacturing firms' performance. In response to this issue, this study shed some light on GHRM bundle practices among manufacturing firms in Palestine and the impact they bring to the organizational performance. The model requires modifications to be aptly adopted by manufacturing firms in Palestine. Last but not least, GHRM practices as a bundle has a significant value to the firms' green development. It is considered an essential tool to engage employees in green practices, thereby enhancing the firms' performance.

\section{References}

[1] Aggarwal, S., \& Sharma, B. (2014). Green HRM: need of the hour. International Journal of Management and Social Science Research Review, 1(8), 63-70.

[2] Ahmad, S. (2015). Green human resource management: policies and practices. Cogent Business \& Management, 2(1), 1030817.

[3] Alfes, K., Shantz, A. D., Truss, C., \& Soane, E. C. (2013). The link between perceived human resource management practices, engagement, and employee behaviour: a moderated mediation model. The International Journal of Human Resource Management, 24(2), 330-351.

[4] Anusingh, L., \& Shikha, G. (2015). Impact of green human resource factors on environmental performance in manufacturing companies: an empirical evidence, 6(1), 23-30.

[5] Aragón-Correa, J. a., Martin-Tapia, I., \& Hurtado-Torres, N. E. (2013). Proactive Environmental Strategies and Employee Inclusion: The Positive Effects of Information Sharing and Promoting Collaboration and the Influence of Uncertainty. SAGE Publications, 26(2), 139-161

[6] Aragón-Correa, J. A. (1998). Strategic proactivity and firm approach to the natural environment. Academy of Management Journal, 41(5), 556-567.

[7] Arulrajah, A. A., Opatha, H. H. D. N. P., \& Nawaratne, N. N. J. (2016). Green human resource management practices: a review. Sri Lankan Journal of Human Resource Management, 5(1), 1.

[8] Bayo-Moriones, A., \& Merino-Díaz de Cerio, J. (2002). Human Resource Management, Strategy, and Operational Performance in the Spanish Manufacturing Industry. M@n@gement, 5(3), 175.

[9] Combs, J., Liu, Y., Hall, A., \& Ketchen, D. (2006). How much do high-performance work practices matter? a meta-analysis of their effects on organizational performance. PERSONNEL PSYCHOLOGY, 59, 501-528.

[10] Deshwal, P. (2015). Green HRM: An organizational strategy of greening people, 1(13), 176-181.

[11] Firdaus, M., Udin, Z. M. (2014). Green human resource management (ghrm) towards sme's: a conceptual view. The 4th International Conference on Technology and Operations Management, 135-140.

[12] Geng, R., Mansouri, S. A., \& Aktas, E. (2017). The relationship between green supply chain management and performance: A metaanalysis of empirical evidences in Asian emerging economies. International Journal of Production Economics, 183, 245-258.

[13] Govindarajulu, N., \& Daily, B. F. (2004). Motivating employees for environmental improvement. Industrial management \& data systems, 104(4), 364-372.

[14] Guerci, M., Longoni, A., \& Luzzini, D. (2016). Translating stakeholder pressures into environmental performance-the mediating role of green HRM practices. The International Journal of Human Resource Management, 27(2), 262-289.

[15] Haddock-Millar, J., Sanyal, C., \& Müller-Camen, M. (2016). Green human resource management: a comparative qualitative case study of a United States multinational corporation. The International Journal of Human Resource Management, 27(2), 192-211.

Hair, Joseph F., Marko Sarstedt, Christian M. Ringle, S. P. G. (2017). Advanced issues in partial least squares structural equation modelling.

Hair, J. F., Sarstedt, M., Hopkins, L., \& Kuppelwieser, V. G. (2014). Partial least squares structural equation modeling (PLSSEM) An emerging tool in business research. European Business Review, 26(2)

[18] Hart, S. L. (1995). A natural-resource-based view of the firm. Academy of management review, 20(4), 986-1014.

[19] Hosain, M. S., \& Rahman, M. S. (2016). Green Human Resource Management: A Theoretical Overview.

[20] Jabbour, C. J. C., \& de Sousa Jabbour, A. B. L. (2016). Green Human Resource Management and Green Supply Chain Management: linking two emerging agendas. Journal of Cleaner Production, 112, 1824-1833.

[21] Jabbour, C. J. C. (2015). Environmental training and environmental management maturity of Brazilian Companies with ISO14001: empirical evidence. Journal of Cleaner Production, 96, 331-338

Jabbour, C. J. C., de Sousa Jabbour, A. B. L., Govindan, K., Teixeira, A. A., \& de Souza Freitas, W. R. (2013). Environmental management and operational performance in automotive companies in Brazil: the role of human resource management and lean manufacturing. Journal of Cleaner Production, 47, 129-140

[23] Jabbour, C. J. C., \& Santos, F. C. A. (2008). The central role of human resource management in the search for sustainable organizations. The International Journal of Human Resource Management, 19(12), 2133-2154

[24] Jadhav, J. R., \& Mantha, S. S. (2013). Practice Bundles for Integrated Green-Lean Manufacturing Systems. International Journal of Computer Applications, 7, 975-8887.

[25] Longoni, A., Luzzini, D., \& Guerci, M. (2016). Deploying Environmental Management Across Functions: The Relationship Between Green Human Resource Management and Green Supply Chain Management. Journal of Business Ethics, 1-15.

[26] Mandip, G. (2012). Green HRM: People Management Commitment to Environmental Sustainability. Research Journal of Recent Sciences, 1, 244-252.

[27] Margaretha, M., \& Saragih, S. (2013, March). Developing new corporate culture through green human resource practice. In International Conference on Business, Economics, and Accounting (pp. 1-10).

[28] Masri, H. A., \& Jaaron, A. A. M. (2017). Assessing green human resources management practices in Palestinian manufacturing context: An empirical study. Journal of Cleaner Production, 143, 474-489.

[29] Opatha, H. H. D. N. P., \& Arulrajah, A. A. (2014). Green human resource management: Simplified general reflections. International Business Research, 7(8), 101

[30] Paillé, P., Chen, Y., Boiral, O., \& Jin, J. (2014). The Impact of Human Resource Management on Environmental Performance: An Employee-Level Study, 121(3), 451-466.

[31] Patel, N. P. (2014). Green HR: A Paradigm Shift in Human Resource Management Philosophy. Brazilian Online Journal, 2, 10

[32] Peng, D. X., \& Lai, F. (2012). Using partial least squares in operations management research: A practical guideline and summary of past research. Journal of Operations Management, 30(6), 467-480

33] PSE. (2016). Palestine Securities Exchange-PSE Listed Companies. [34] Rani, S., \& Mishra, K. (2014). Green HRM: Practices and strategic implementation in the organizations. International Journal on Recent and Innovation Trends in Computing and Communication, 2(11), 3633-3639.

[35] Renwick, D. W., Redman, T., \& Maguire, S. (2013). Green human resource management: A review and research agenda. International Journal of Management Reviews, 15(1), 1-14

[36] Rezaei-Moghaddam, K. (2016). Green management of human resources in organizations: An approach to the sustainable environmental management. Journal of Agricultural Technology, 12(3), 509-522.

[37] Tadić, I., \& Pivac, S. (2014). Defining Human Resource" Bundles" and Its' Correlation with Companies' Financial Performances. International journal of Social, Management, Economics and Business Engineering, 8(4), 1025-1029.

[38] Tang, G., Chen, Y., Jiang, Y., Paillé, P., \& Jia, J. (2017). Green human resource management practices: scale development and validity. Asia Pacific Journal of Human Resources. 
[39] Teixeira, A. A., Jabbour, C. J. C., \& Jabbour, A. B. L. de S. (2012) Relationship between green management and environmental training in companies located in Brazil: A theoretical framework and case studies. International Journal of Production Economics, 140(1), 318-329.

[40] Teixeira, A. A., Jabbour, C. J. C., de Sousa Jabbour, A. B. L. Latan, H., \& de Oliveira, J. H. C. (2016). Green training and green supply chain management: evidence from Brazilian firms. Journal of Cleaner Production, 116, 170-176.

[41] Vazquez, D. A., Jabbour, C. J. C., Plaza-Ubeda, J. A., \& de Sousa Jabbour, A. B. L. (2016, January). Stakeholders, Green Human Resource Management (GHRM) and environmental proactivity in Brazil. In Academy of Management Proceedings (Vol. 2016, No. 1, p. 12686). Academy of Management.

[42] Wagner, M. (2011). Environmental management activities and sustainable HRM in German manufacturing firms-incidence, determinants, and outcomes. German Journal of Human Resource Management, 25(2), 157-177.

[43] Wagner, M. (2013). Green Human Resource Benefits: Do they Matter as Determinants of Environmental Management System Implementation? Journal of Business Ethics, 114(3), 443-456.

[44] Wood, G. (2014). Human Resource Management and the Institutional Perspective. Rout ledge.

[45] Younis, H., Younis, H., Sundarakani, B., Sundarakani, B., Vel, P., \& Vel, P. (2016). The impact of implementing green supply chain management practices on corporate performance. Competitiveness Review, 26(3), 216-245.

[46] Yusoff, Y. M., Othman, N. Z., Fernando, Y., Amran, A., Surienty, L., \& Ramayah, T. (2015). Conceptualization of green human resource management: an exploratory study from Malaysian-based multinational companies. International Journal of Business Management \& Economic Research, 6(3), 158-166.

[47] Zhu, Q., Sarkis, J., \& Lai, K. (2012). Examining the effects of green supply chain management practices and their mediations on performance improvements. International Journal of Production Research, 50(5), 1377-1394. 